\title{
Common Fixed Points of Four Mapping in Metric Spaces
}

\author{
S. D. Diwan ${ }^{1}$, A. K. Thakur $^{2}$, Hiral Raja ${ }^{3}$ \\ ${ }^{1}$ Sant Guru Ghasidas Govt. P. G. College Dhamtari (C.G.) India \\ ${ }^{2}$ Dr. C. V. Raman University Bilaspur (C.G.) India \\ ${ }^{3}$ Research Scholar Dr. C. V. Raman University Bilaspur (C.G.) India
}

\begin{abstract}
In this paper, we prove some common fixed point theorems for four mappings satisfying fractional inequalities using common limit property in metric spaces. Our results generalize and improve upon, among several results of fixed point arena including he results of Fisher [5], Jungck [7] and Badshah et al. [2], Lohani and Badshah [11].
\end{abstract}

2010 Mathematics Subject Classification: 54H25, 47H10

Keywords: weakly compatible mappings, common limit property, property (E.A), common fixed points.

\section{Introduction}

Jungck [6] generalized Banach contraction principle [3] for a pair of commuting mappings. Afterward, study of common fixed points of mappings satisfying some contractive type condition has been center of vigorous research activity and a number of interesting results have been obtained using commutativity and its weaker forms such as weak commutativity [18], compatibility [7], Rweak commutativity [12], semi- compatibility [4], compatibility of type (A) [8], compatibility of type (B) [16], compatible mappings of type (T) [17], biased maps [9] and weak compatibility [10] etc. Pant [12, 13, 14, 15] studied fixed point results for the class of non-compatible mappings.

On the other hand Amari and Moutawakil [1] introduced the notion of prop- erty (E.A) which contains the classes of compatible as well non-compatible map- pings. Sintunavarat and Kumam [19] defined the notion of (CLRg) property. It has been noticed that (CLRg) property never requires completeness (or closedness) of subspaces (also see [20, 21]).

Recently, Badshah et al. [2] proved common fixed point theorem by using a fractional inequality and compatible mappings instead of commuting mappings. In this paper, we prove results of Badshah et al. [2] Using (CLRg) property and (E. A) property. Our results generalize and improve upon, among several results of fixed point arena including the results of Fisher [5], Jungck [7] and Badshah et al. [2], Lohani and Badshah [11].

\section{Preliminaries}

Sessa [18] introduced the notion of weak commutativity:

Definition 2.1. [18] Two self-mappings $S$ and $T$ of a metric space $(X, d)$ are said to be weakly commuting if

$\mathrm{d}(\mathrm{ST} \mathrm{x}, \mathrm{T} \mathrm{Sx}) \leq \mathrm{d}(\mathrm{Sx}, \mathrm{T} \mathrm{x}), \mathbf{f}$ or all $\mathrm{x} \in \mathrm{X}$,

It is clear that two commuting mappings are weakly commuting but the converse is not true as is shown in [18].

Definition 2.2. [7] Two self-mappings $S$ and $T$ of a metric space $(\mathrm{X}, \mathrm{d})$ are said to be compatible if

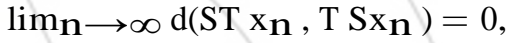

whenever $\left\{x_{n}\right\}$ is a sequence in $X$ such that

$\lim _{\mathbf{n} \rightarrow \infty} \mathrm{Sx}_{\mathbf{n}}=\lim _{\mathbf{n}} \rightarrow \infty \mathrm{T} \mathrm{x}_{\mathbf{n}}=\mathrm{t}$,

for some $\mathrm{t} \in \mathrm{X}$.

Obviously, two weakly commuting mappings are compatible, but the converse is not true as shown in [7].

Definition 2.3. [10] Two self-mappings $S$ and $T$ of a metric space $(X, d)$ are said to be weakly compatible if they commute at their coincidence points, i.e. if $\mathrm{Su}=\mathrm{T} \mathrm{u}$ for some $\mathrm{u} \in \mathrm{X}$, then $\mathrm{ST} \mathrm{u}=\mathrm{T} \mathrm{Su}$. It is easy to see that two compatible mappings are weakly compatible.

Definition 2.4 [1] Two self-mappings $S$ and $T$ of a metric space $(X, d)$ are said to satisfy the property (E.A) if there exists a sequence $\left\{x_{\mathbf{n}}\right\}$ in $X$ such that

$\lim _{\mathbf{n}} \rightarrow \infty \mathrm{Sx}_{\mathbf{n}}=\lim _{\mathbf{n}} \rightarrow \infty \mathrm{T} \mathrm{x}_{\mathbf{n}}=\mathrm{t}$,

for some $\mathrm{t} \in \mathrm{X}$.

Definition 2.5 [19] Two self-mappings $\mathrm{S}$ and $\mathrm{T}$ of a metric space $(X, d)$ are said to satisfy the common limit in the range of $T$ property if there exists a sequence $\left\{x_{n}\right\}$ in $\mathrm{X}$ such that

$\lim _{\mathrm{n} \rightarrow \infty} \mathrm{Sx}_{\mathrm{n}}=\lim _{\mathrm{n} \rightarrow \infty} \mathrm{T} \mathrm{x}_{\mathrm{n}}=\mathrm{Tu}$,

for some $u \in X$.

In what follows, the common limit in the range of $\mathrm{g}$ property will be denoted by the (C LRT) property.

Now, we give examples of mappings $f$ and $g$ which satisfy the (C LRT) property.

Example 2.6. Let $X=[0, \infty)$ with the usual metric on $X$. Define $\mathrm{S}, \mathrm{T}: \mathrm{X} \rightarrow \mathrm{X}$ by 


\section{International Journal of Science and Research (IJSR) \\ ISSN (Online): 2319-7064}

Index Copernicus Value (2013): 6.14 | Impact Factor (2015): 6.391

$\mathrm{Sx}=\mathrm{x} / 2$ and $\mathrm{T} \mathrm{x}=2 \mathrm{x}$ for all $\mathrm{x} \in \mathrm{X}$. Consider the sequence $\left\{x_{\mathbf{n}}\right\}=\{1 / \mathbf{n}\}$. Since

$\operatorname{Lim}_{\mathbf{n} \rightarrow \infty} \mathbf{S x}_{\mathbf{n}}=\lim _{\mathbf{n} \rightarrow \infty} \mathrm{T} \mathbf{x}_{\mathbf{n}}=0=\mathrm{T} 0$,

Therefore $\mathrm{S}$ and $\mathrm{T}$ satisfy the (C LRT) property.

Example 2.7. Let $X=[0, \infty)$ with the usual metric on $X$. Define $\mathrm{S}, \mathrm{T}: \mathrm{X} \rightarrow \mathrm{X}$ by $\mathrm{Sx}=\mathrm{x}+2$ and $\mathrm{T} \mathrm{x}=3 \mathrm{x}$ for all $\mathrm{x} \in$ $\mathrm{X}$. Consider the sequence $\left\{\mathrm{x}_{\mathbf{n}}\right\}=\{1+1 / \mathbf{n}\}$. Since $\lim _{\mathbf{n}} \rightarrow \infty \mathrm{Sx}_{\mathbf{n}}=\lim _{\mathbf{n}} \rightarrow \infty \mathrm{T} \mathrm{x}_{\mathbf{n}}=3=\mathrm{T} 1$, Therefore $\mathrm{S}$ and $\mathrm{T}$ satisfy the (C LRT) property.

Remark 2.8. It is clear from the Jungck's definition [6] that two self-mappings $\mathrm{S}$ and $\mathrm{T}$ of a metric space $(\mathrm{X}, \mathrm{d})$ will be non-compatible if there exists atleast one sequence

$\left\{x_{n}\right\}$ in $X$ such that

$\lim _{\mathbf{n} \rightarrow \infty} \mathrm{Sx}_{\mathbf{n}}=\lim _{\mathbf{n}} \rightarrow \infty \mathrm{T} \mathrm{x}_{\mathbf{n}}=\mathrm{t}$, f or some $\mathrm{t} \in \mathrm{X}$, but $\lim _{\mathbf{n}} \rightarrow \infty \mathrm{d}\left(\mathrm{ST} \mathrm{x}_{\mathbf{n}}, \mathrm{TSx}_{\mathbf{n}}\right)$ is either non-zero or nonexistent.

Thus, two non-compatible self-mappings of a metric space (X, d) satisfy the property (E.A).

\section{Main Results}

Lemma 3.1. Let $A, B, S$ and $T$ be self-mappings from a metric space $(X, d)$ into itself satisfying following conditions:

(3.1) The pairs $\{A, S\}$ and $\{B, T\}$ are weakly compatible;

$$
d(A x, B y) \leq a \frac{[d(S x, A x)]^{3}+[d(T y, B y)]^{3}}{[d(S x, A x)]^{2}+[d(T y, B y)]^{2}}+b d(S x, T y)
$$

for all $x, y \in X$ where $a, b \geq 0$ and $a+b<1$. If there exists $\mathrm{u}, \mathrm{v} \in \mathrm{X}$ such that $\mathrm{Au}=\mathrm{Su}=\mathrm{Bv}=\mathrm{T} \mathrm{v}=\mathrm{t}$ for some $t$ in $X$ then $t$ is the unique fixed point of $A, B, S$ and $\mathrm{T}$.

Proof: Since $\{\mathrm{A}, \mathrm{S}\}$ is weakly compatible and $\mathrm{Au}=\mathrm{Su}=$ $\mathrm{t}$, we have At $=\mathrm{ASu}=\mathrm{SAu}=\mathrm{St}$. We claim that $\mathrm{At}=\mathrm{t}$, if not then using (3.2), we have

$$
\begin{aligned}
\mathrm{d}(\mathrm{At}, \mathrm{t})=\mathrm{d}(\mathrm{At}, \mathrm{Bv}) & \leq \mathrm{a}\left[\frac{[\mathrm{d}(\mathrm{St}, \mathrm{At})]^{3}+[\mathrm{d}(\mathrm{T} \mathrm{v}, \mathrm{Bv})]^{3}}{[\mathrm{St}, \mathrm{At})]^{2}+[\mathrm{d}(\mathrm{T} \mathrm{v}, \mathrm{Bv})]^{2}}+\mathrm{bd}(\mathrm{St}, \mathrm{T} \mathrm{v})\right. \\
& \leq \mathrm{a}[\mathrm{d}(\mathrm{St}, \mathrm{At})+\mathrm{d}(\mathrm{Tv}, \mathrm{Bv})]+\mathrm{bd}(\mathrm{At}, \mathrm{t}) \\
& \leq \mathrm{bd}(\mathrm{At}, \mathrm{t}),
\end{aligned}
$$

which is a contradiction. Hence At $=t$. Thus we have At $=$ $\mathrm{St}=\mathrm{t}$. Similarly we can prove that $\mathrm{Bt}=\mathrm{Tt}=\mathrm{t}$. Hence $\mathrm{t}$ is common fixed point of mappings $\mathrm{A}, \mathrm{B}, \mathrm{S}$ and $\mathrm{T}$.

If possible suppose that $\mathrm{t}$ and $\mathrm{z}$ are two distinct common fixed points of $\mathrm{A}, \mathrm{B}, \mathrm{S}$ and $\mathrm{T}$, then using (3.2), we have

$$
\begin{aligned}
\mathrm{d}(\mathrm{t}, \mathrm{z})=\mathrm{d}(\mathrm{At}, \mathrm{Bz}) \leq \mathrm{a} \frac{[\mathrm{d}(\mathrm{St}, \mathrm{At})]^{3}+[\mathrm{d}(\mathrm{T} z, B z)]^{3}}{[\mathrm{~d}(\mathrm{St}, \mathrm{At})]^{2}+[\mathrm{d}(\mathrm{T} \mathrm{z}, \mathrm{Bz})]^{2}}+\mathrm{bd}(\mathrm{St}, \mathrm{Tz}) \\
\quad \leq \mathrm{a}[\mathrm{d}(\mathrm{St}, \mathrm{At})+\mathrm{d}(\mathrm{Tz}, \mathrm{Bz})]+\mathrm{bd}(\mathrm{St}, \mathrm{Tz}) \\
\leq \mathrm{a}[\mathrm{d}(\mathrm{t}, \mathrm{t})+\mathrm{d}(\mathrm{z}, \mathrm{z})]+\mathrm{bd}(\mathrm{t}, \mathrm{z}) \\
\text { i.e. } \mathrm{d}(\mathrm{t}, \mathrm{z}) \leq \mathrm{bd}(\mathrm{t}, \mathrm{z}),
\end{aligned}
$$

which is a contradiction, hence $t=z$. Therefore $t$ is unique common fixed point of $\mathrm{A}, \mathrm{B}, \mathrm{S}$ and $\mathrm{T}$.
Theorem 3.2. Let $\mathrm{A}, \mathrm{B}, \mathrm{S}$ and $\mathrm{T}$ be self-mappings from a metric space (X, d) into itself satisfying (3.1), (3.2) and following conditions:

(3.3) $\mathrm{A}(\mathrm{X}) \subseteq \mathrm{T}(\mathrm{X})$ and $\mathrm{B}(\mathrm{X}) \subseteq \mathrm{S}(\mathrm{X})$,

(3.4) One of the pairs $(A, S)$ or $(B, T)$ satisfying property (E.A.)

(3.5) One of the $\mathrm{A}(\mathrm{X}), \mathrm{B}(\mathrm{X}), \mathrm{S}(\mathrm{X})$ and $\mathrm{T}(\mathrm{X})$ is closed subspace of $\mathrm{X}$.

Then $\mathrm{A}, \mathrm{B}, \mathrm{S}$ and $\mathrm{T}$ have a unique common fixed point in $\mathrm{X}$.

Proof: Suppose that the pair $(\mathrm{B}, \mathrm{T})$ satisfies property (E.A), then there exists a sequence $\left\{x_{n}\right\}$ in $X$ such that $\lim _{n \rightarrow \infty} B x_{n}=\lim _{n \rightarrow \infty} T x_{n}=$ for somet $\in X$

Further, since $\mathrm{B}(\mathrm{X}) \subseteq \mathrm{S}(\mathrm{X})$, there exists a sequence $\left\{\mathrm{y}_{\mathbf{n}}\right\}$ in $X$ such that $B_{\mathbf{n}}=S_{\mathbf{n}}$. Hence $\lim _{\mathbf{n} \rightarrow \infty} \operatorname{Sy}_{\mathbf{n}}=\mathrm{t}$.

Now we claim that $\lim _{\mathbf{n}} \rightarrow \infty \mathrm{Ay}_{\mathbf{n}}=\mathrm{t}$. If possible suppose that $\lim _{\mathbf{n}} \rightarrow \infty \mathrm{Ay}_{\mathbf{n}}=\mathrm{t} \mathbf{1} \neq \mathrm{t}$, then putting $\mathrm{x}=$ $\mathrm{y}_{\mathbf{n}}, \mathrm{y}=\mathrm{x}_{\mathbf{n}}$ in (3.2) we have.

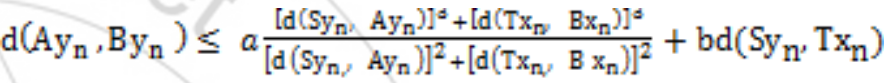

$$
\begin{aligned}
& \leq \mathrm{a}\left[\mathrm{d}\left(\mathrm{Sy}_{\mathbf{n}}, \mathrm{Ay}_{\mathbf{n}}\right)+\mathrm{d}\left(\mathrm{T} \mathrm{x}_{\mathbf{n}},\right.\right.
\end{aligned}
$$$$
\mathrm{Bx} \mathbf{n})]+\operatorname{bd}\left(\mathrm{Sy}_{\mathbf{n}}, \mathrm{T} \mathbf{x}_{\mathbf{n}}\right) \text {. }
$$

Taking limit as $\mathrm{n} \rightarrow \infty$, we get

$$
\begin{aligned}
& \mathrm{d}\left(\mathrm{t}_{1}, \mathrm{t}\right) \leq \mathrm{ad}\left(\mathrm{t}, \mathrm{t}_{1}\right) \\
& (1-\mathrm{a}) \mathrm{d}\left(\mathrm{t}, \mathrm{t}_{1}\right) \leq 0
\end{aligned}
$$

or

as $0 \leq \mathrm{a}<1$, we have $\mathrm{d}\left(\mathrm{t}, \mathrm{t}_{1}\right)=0$. Hence $\mathrm{t}=\mathrm{t}_{1}$, thus we have $\lim _{\mathbf{n} \rightarrow \infty} \operatorname{Ay}_{\mathbf{n}}=\mathrm{t}$.

Now suppose that $S(X)$ is closed subspace of $X$ then there exists $\mathrm{u} \in \mathrm{X}$ such that $\mathrm{t}=\mathrm{Su}$. Subsequently, we have

$\lim _{n \rightarrow \infty} A y_{n}=\lim _{n \rightarrow \infty} B x_{n}=\lim _{n \rightarrow \infty} T_{n}=\lim _{n \rightarrow \infty} S y_{n}=t=S u$

Next we shall claim that $\mathrm{Au}=\mathrm{Su}$. Taking $\mathrm{x}=\mathrm{u}, \mathrm{y}=\mathrm{x}_{\mathbf{n}}$ in (3.2), we get

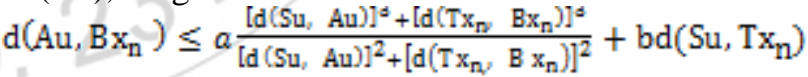

$$
\begin{aligned}
& \leq \mathrm{a}\left[\mathrm{d}(\mathrm{Su}, \mathrm{Au})+\mathrm{d}\left(\mathrm{Tx}_{\mathbf{n}}, \mathrm{Bx}_{\mathbf{n}}\right)\right]+\mathrm{bd}\left(\mathrm{Su}, \mathrm{Tx}_{\mathbf{n}}\right) . \\
& \text { Taking limit as } n \rightarrow \infty \text {, we have } \\
& \mathrm{d}(\mathrm{Au}, \mathrm{t}) \leq \mathrm{ad}(\mathrm{t}, \mathrm{Au})
\end{aligned}
$$

which is a contradiction. Hence we have $\mathrm{Au}=\mathrm{t}$. Thus $\mathrm{Au}$ $=\mathrm{Su}=\mathrm{t}$.

Further, since $\mathrm{A}(\mathrm{X}) \subseteq \mathrm{T}(\mathrm{X})$, there exists $\mathrm{v}$ in $\mathrm{X}$ such that $\mathrm{Au}=\mathrm{Tv}$. Thus we have $\mathrm{Au}=\mathrm{Su}=\mathrm{T} v=\mathrm{t}$. Now, we show that $\mathrm{Bv}=\mathrm{T} v$. For taking $\mathrm{x}=\mathrm{u}, \mathrm{y}=\mathrm{v}$ in (3.2), we have

$$
\begin{aligned}
& \mathrm{d}(\mathrm{Au}, \mathrm{Bv}) \leq \mathrm{a} \quad \frac{[\mathrm{d}(\mathrm{Su}, \mathrm{Au})]^{3}+[\mathrm{d}(\mathrm{T} \mathrm{v}, \mathrm{Bv})]^{3}}{[\mathrm{~d}(\mathrm{Su}, \mathrm{Au})]^{2}+[\mathrm{d}(\mathrm{T} \mathrm{v}, \mathrm{Bv})]^{2}}+\mathrm{bd}(\mathrm{Su}, \mathrm{T} v) \\
& \leq \quad \mathrm{a}[\mathrm{d}(\mathrm{Su}, \mathrm{Au})+\mathrm{d}(\mathrm{Tv}, \mathrm{Bv})]+\mathrm{bd}(\mathrm{Su}, \mathrm{T} v) \\
& \mathrm{d}(\mathrm{t}, \mathrm{Bv}) \leq \mathrm{ad}(\mathrm{t}, \mathrm{Bv})
\end{aligned}
$$

which is a contradiction, therefore $\mathrm{t}=\mathrm{Bv}$. Hence $\mathrm{Bv}=\mathrm{T}$ $\mathrm{v}=\mathrm{t}$. Thus we have

$$
\mathrm{Au}=\mathrm{Su}=\mathrm{Bv}=\mathrm{T} \mathrm{v}=\mathrm{t} .
$$

A similar argument works if we assume $\mathrm{T}(\mathrm{X})$ to be closed. 


\section{International Journal of Science and Research (IJSR) \\ ISSN (Online): 2319-7064}

Index Copernicus Value (2013): 6.14 | Impact Factor (2015): 6.391

On the other hand if $\mathrm{A}(\mathrm{X})$ is closed, there exists $\mathrm{u}$ ' in $\mathrm{X}$ such that $\mathrm{Au}=\mathrm{t}$ since

$\mathrm{A}(\mathrm{x}) \subseteq \mathrm{T}(\mathrm{x})$, there exists $\mathrm{v}^{\prime}$ in $\mathrm{X}$ such that $\mathrm{Tv} \mathrm{v}^{\prime}=\mathrm{t}$. Using

(3.2) with $\quad x=x_{n_{a}} y=v^{\prime}, \quad$ we have

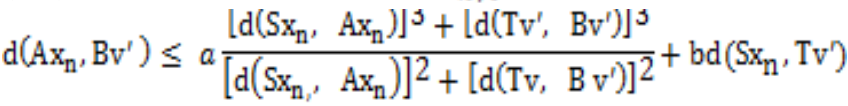

or

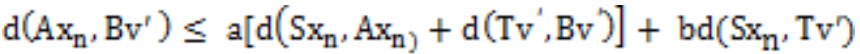

Taking limit as $\mathrm{n} \rightarrow \infty$

$$
\mathrm{d}\left(\mathrm{t}, \mathrm{Bv} \mathrm{v}^{\prime}\right) \leq \operatorname{ad}\left(\mathrm{t}, \mathrm{Bv}{ }^{\prime}\right)
$$

Which is a contraction therefore $\mathrm{Bv}^{\prime}=\mathrm{t}$. Since $\mathrm{B}(\mathrm{x}) \subseteq \mathrm{S}(\mathrm{x})$, there exists $u^{m}$ in $\mathrm{X}$, such that $\mathrm{S} u^{\mathrm{m}}=\mathrm{t}$ using 3.2 we can easily show that $\mathrm{A} u^{m}=\mathrm{S} u^{m}=\mathrm{B} v^{\prime}=\mathrm{T} v^{\prime}=\mathrm{t}$

A similarly argument can be produced if $\mathrm{B}(\mathrm{X})$ is closed. Also if the pair (A, S) satisfies (E.A) property we will get similar result. Now appealing to Lemma (3.1) in all cases, we conclude that $\mathrm{A}, \mathrm{B}, \mathrm{S}$ and $\mathrm{T}$ have a unique common fixed point $\mathrm{t}$ in $\mathrm{X}$.

Corollary 3.3. Let $(X, d)$ be a metric space and $A, T: X \rightarrow$ $\mathrm{X}$ be two self mappings satisfying the following conditions

(3.6) The pair $\{A, T\}$ is weakly compatible;

$$
d(A x, A y) \leq a \frac{[d(T x, A x)]^{3}+[d(T y, A y)]^{3}}{[d(T x, A x)]^{2}+[d(T y, A y)]^{2}}+b d(T x, T y)
$$

for all $\mathrm{x}, \mathrm{y} \in \mathrm{X}$, where $\mathrm{a}, \mathrm{b}>0$ and $\mathrm{a}+\mathrm{b}<1$

(3.8) $\mathrm{A}(\mathrm{X}) \subseteq \mathrm{T}(\mathrm{X})$

(3.9) The pair (A, T) satisfy properly (E.A.)

(3.10) $\mathrm{A}(X)$ or $\mathrm{T}(X)$ is closed subspace of $X$.

Then $\mathrm{A}$ and $\mathrm{T}$ have a unique common fixed point in $\mathrm{X}$.

Corollary 3.4. Let A, B, S and T be self-mappings from a metric space $(X, d)$ into itself satisfying (3.1),(3.2),(3.3),(3.5) and if either the pair (A,S) or $(\mathrm{B}, \mathrm{T})$ is non- compatible. Then $\mathrm{A}, \mathrm{B}, \mathrm{S}$ and $\mathrm{T}$ have a unique common fixed point in $\mathrm{X}$.

Theorem 3.5. Let $(X, d)$ be a metric space $A, B, S, T$ : $X \rightarrow X$ be self-mappings satisfying (3.1),(3.2),(3.3) and either the pair $(A, S)$ satisfies $(C L R A)$ property or the pair $(\mathrm{B}, \mathrm{T})$ satisfies (CLRB ) property. Then $\mathrm{A}, \mathrm{B}, \mathrm{S}$ and $\mathrm{T}$ have a unique common fixed point in $\mathrm{X}$. property, then there exists a sequence $\left\{x_{n}\right\}$ in $X$ such that

$\lim _{n \rightarrow \infty} B x_{n}=\lim _{n \rightarrow \infty} T x_{n}=B x$ for somex $\in X$

Since $B(X) \subseteq S(X)$, there exists $u$ in $X$ Such that $\mathrm{Bx}=\mathrm{Su}$. We claim that $\mathrm{Au}=\mathrm{Su}=\mathrm{t}$. For this using (3.2) with $\mathrm{x}=\mathrm{u}, \mathrm{y}=x_{n}$, we have

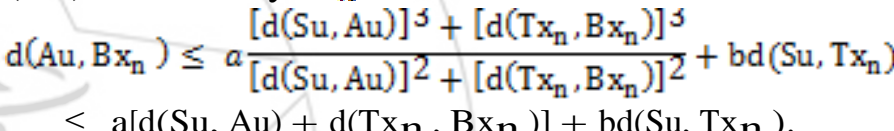

Letting $\mathrm{n} \rightarrow \infty$, we have

$$
\mathrm{d}(\mathrm{Au}, \mathrm{Su}) \leq \mathrm{ad}(\mathrm{Su}, \mathrm{Au}),
$$

which is a contradiction, hence $\mathrm{Au}=\mathrm{Su}$. Thus we have $\mathrm{Au}=\mathrm{Su}=\mathrm{Bx}=\mathrm{t}$. Further, since $\mathrm{A}(\mathrm{X}) \subseteq \mathrm{T}(\mathrm{X})$, there exists $v$ in $X$ such that $\mathrm{Au}=\mathrm{T} v$. Now we show that $\mathrm{Bv}$ $=\mathrm{T} v$. Using (3.2) with $\mathrm{x}=\mathrm{u}, \mathrm{y}=\mathrm{v}$, we have

Proof: Suppose the pair (B, T ) satisfies (C LRB)

$$
\begin{aligned}
& \mathrm{d}(\mathrm{Au}, \mathrm{Bv}) \leq \mathrm{a} \quad \begin{array}{l}
{[\mathrm{d}(\mathrm{Su}, \mathrm{Au})]^{3}+[\mathrm{d}(\mathrm{Tv}, \mathrm{Bv})]^{3}} \\
{[\mathrm{~d}(\mathrm{Su}, \mathrm{Au})]^{2}+[\mathrm{d}(\mathrm{Tv}, \mathrm{Bv})]^{2}}
\end{array}+\mathrm{bd}(\mathrm{Su}, \mathrm{T} v) \\
& \leq \mathrm{a}[\mathrm{d}(\mathrm{Su}, \mathrm{Au})+\mathrm{d}(\mathrm{T} v, \mathrm{Bv})]+\mathrm{bd}(\mathrm{Su}, \mathrm{T} v) \\
& \mathrm{d}(\mathrm{T} v, \mathrm{Bv}) \leq \mathrm{ad}(\mathrm{Tv}, \mathrm{Bv}),
\end{aligned}
$$

which is a contradiction, therefore $\mathrm{Bu}=\mathrm{T}$ v. Thus we have $\mathrm{Au}=\mathrm{Su}=\mathrm{Bv}=\mathrm{tv}=\mathrm{t}$. Hence from Lemma (3.1), $\mathrm{A}$, $\mathrm{B}, \mathrm{S}$ and $\mathrm{T}$ have a unique common fixed point $\mathrm{t}$ in $\mathrm{X}$.

\section{References}

[1] Aamri, M., El Moutawakil, D.: Some new common fixed point theorems under strict contractive conditions. J. Math. Anal. Appl., 270,(2002), 181-188

[2] Badshah, V. H., Chauhan, M. S. and Sharma, D.,Common fixed point theo- rems for compatible mappings, International Journal of Theoretical and Applied Sciences, 1(2), (2009), 79-82.

[3] Banach, S., Sur les operations dans les ensembles absetraits et leurs applications, Fund. Math. 3, (1922), 133-181.

[4] Y.J. Cho, B.K. Sharma and D.R. Sahu, Semicompatibility and fixed points, Math. Japonica, 42(1) (1995), 91-98.

[5] Fisher, B., Common fixed point of four mappings, Bull. Inst. Math. Acad. Scinica, 11: 103(1983).

[6] Jungck, G., Commuting maps and fixed points, Amer. Math. Monthly, 83:261 (1976).

[7] Jungck, G., Compatible mappings and common fixed points, Internat. J. Math. and Math. Sci., 9: 771 (1986).

[8] Jungck, G., Murthy, P. P. and Cho, Y. J., Compatible mappings of type (A) and common fixed points, Math. Japonica 38(2)(1993), 381-390.

[9] Jungck, G., Pathak, H. K., Fixed points via 'Biased

\section{Volume 5 Issue 5, May 2016}




\section{International Journal of Science and Research (IJSR) \\ ISSN (Online): 2319-7064}

Index Copernicus Value (2013): 6.14 | Impact Factor (2015): 6.391

maps', Proc. Amer. Math. Soc., 123(7), 2049-2060 (1995)

[10] Jungck, G. and Rhoades, B. E., Fixed points for setvalued functions without continuity, Indian J. Pure and Appl. Math., 29(3)(1998), 227-238.

[11]Lohani, P.C. and Badshah, V.H., Compatible mappings and common fixed point for four mappings, Bull. Cal. Math. Soc., 90, (1998), 301-308.

[12] Pant, R. P., Common fixed points of noncommuting mappings, Journal of Math-ematical Analysis and Applications,vol.188,no. 2, (1994), 436-440.

[13] Pant, R. P., Common fixed point theorems for Contractive maps, Journal Mathematical Analysis and Applications, vol. 226, no. 1, (1998), 251-258.

[14] Pant, R. P., Common fixed points of Lipschitz type mapping pairs, Journal Mathematical Analysis and Applications, vol. 240, no. 1, (1999), 280-283.

[15] Pant, R. P., Discontinuity and fixed points, Journal of Mathematical Analysis and Applications, Vol.240, no.1, (1999),284-289.

[16] Pathak H. K. and Khan M. S., Compatible mappings of type (B) and common fixed point theorems of Gregus type, Czechoslovak Math. J. 45(120)(1995), 685-698.

[17] Pathak H. K., Kang S. M., Cho Y. J. and Jung J. S., Gergus type common fixed point theorems for compatible mappings of type (T) and variation inequalities, Publ. Math. 46(1995), 285-299.

[18] Sessa, S., On a weak commutativity condition of mappings in fixed point considerations, Publ. Inst. Math. 32 : (46), (1982), 149.

[19] Sintunavarat, W. and Kuman, P., Common fixed point theorems for a pair of weakly compatible mappings in fuzzy metric spaces, Journal of Applied Mathe- matics, Vol. 2011 (2011), Artcal ID 637958, 14 pages.

[20] Sintunavarat, W. and Kuman, P., Common fixed points for R-weakly commuting in fuzzy metric spaces, Annali dell'Universita di Ferrara, DOI:10.1007/S1 1565-012-0150-z (in Press).

[21] Sintunavarat, W. and Kuman, P., Fixed point theorems for a generalized intu- itionistic fuzzy contraction in intuitionistic fuzzy metric spaces, Thai J. Math.10 (1) (2012) 123-135. 